\title{
It is all in the mix: The interactive effect of music tempo and mode on in-store sales
}

\author{
Klemens M. Knoferle • Eric R. Spangenberg • \\ Andreas Herrmann • Jan R. Landwehr
}

Published online: 7 December 2011

(C) Springer Science+Business Media, LLC 2011

\begin{abstract}
Though practitioners have relied on tempo as a criterion to design in-store music, scant attention has been devoted to the mode of musical selections, and no consideration has been given to the potential for the interactive effects of low-level structural elements of music on actual retail sales. The current research reports a field experiment wherein the positive main effect of slow tempo on actual sales reported by Milliman (J Marketing 46 (3):86-91, 1982, J Cons Res 13 (2):286-289, 1986) is qualified by musical mode. A significant interaction between tempo and mode was evidenced, such that music in a major mode did not vary in effectiveness by tempo while music in a minor mode was significantly more effective when accompanied by a slow tempo. That is, the Milliman effect was eliminated for music in a major mode. Implications of our findings and directions for further research are discussed.
\end{abstract}

Keywords Retail atmospherics $\cdot$ Musical tempo $\cdot$ Musical mode $\cdot$ Linear mixed models

\section{Introduction}

Recognizing the potential for music to influence individual affect, cognition, and behavior, which in turn impacts consumer behavior and decision making, marketers invest substantial resources in an effort to effectively incorporate music into the design of retail environments (e.g., Morrison and Beverland 2003). Considerable research in the field of atmospherics has examined the effects of high level, global properties of music including music versus no-music comparisons (Park and Young 1986), background versus foreground conditions (Yalch and Spangenberg 1993; Morrison et al. 2011), and comparisons of the effects of differing musical genre (Areni and Kim 1993; Wilson 2003; North et al. 2000; North et al. 2003). Related research has focused on properties not inherent to music itself, but on variables

K. M. Knoferle • E. R. Spangenberg $\cdot$ A. Herrmann $•$ J. R. Landwehr

Center for Customer Insight, University of St. Gallen, Bahnhofstrasse 8, 9000 St. Gallen, Switzerland

E. R. Spangenberg $(\bowtie)$

Washington State University, Box 644750, Pullman, WA 99164-4750, USA

e-mail: ers@wsu.edu 
arising either from the interplay between music and the environment (e.g., fit of music and store image, Vida et al. 2007; interaction between music and scent, Spangenberg et al. 2005), or the interplay between music and participant (e.g., shopper's familiarity with the music, Yalch and Spangenberg 2000; subjective liking, Vida et al. 2007; musical preferences, Caldwell and Hibbert 2002). For comprehensive reviews of previously identified effects of music in a marketing context, see Kellaris (2008), Garlin and Owen (2006), Hargreaves and North (1997), and Turley and Milliman (2000).

Little research, however, has studied the direct relationship between low-level, structural properties of in-store music and outcome variables. Milliman's (1982) seminal work examining the effects of a structural property-tempo-of musical selections on supermarket shoppers' behaviors - spending - unfortunately did not stimulate a large stream of follow-up research. In fact, to our knowledge, there is no published work to date examining the combined impact of more than one structural property of music on consumer responses in a realistic field setting. This dearth of research represents a gap in our understanding, often leaving those designing and selecting environmental music reliant on little more than partially informed guesswork with regard to music's structural properties. It can be argued that knowledge regarding the effects of low-level musical properties-which are considered the building blocks used by composers and musicians, as well as prerequisites to higher-level musical properties like genre, fit, or liking - is critical to the systematic design of effective in-store music.

The current research begins to address this gap in our knowledge by examining how the mode and tempo of environmental music affects sales in a retail context. Although in-store music has attracted much "applied" research activity over the past 30 years, the experiment reported herein is the first to demonstrate the interactive effects for the two low-level structural properties of music, tempo, and mode. Further, we extend laboratory findings regarding structural properties of music to real-world consumer decision making with actual financial implications. Knowledge about the impact of the structural properties of music can facilitate scientific selection of effective in-store music, thereby enabling practitioners to move beyond guessing or relying on intuition.

Below, previous research regarding how selected structural properties of in-store music may impact consumer behavior is summarized. Following that, a field experiment is reported wherein tempo and mode of musical selections are manipulated and effects upon actual retail sales are measured. Finally, implications of our findings as well as avenues for future research are discussed.

\section{Background and research questions}

\subsection{Structural properties of music}

Music is categorized by the objective structural properties of time, pitch, and texture (Bruner 1990). Examples of properties along the time dimension are tempo, meter, rhythm, and phrasing, while the pitch dimension includes the properties of mode, harmony, melodic contour, and ambitus. The dimension of texture includes timbre- 
a complex function of log attack time, spectral centroid, and spectral flux (McAdams et al. 1995) — as well as instrumentation, volume, and dynamics. To the composer, musician, or sound designer, these properties provide the means to systematically change the overall nature of the music. On the listener's side, relative property configuration not only determines cognitive and affective responses to music, but also influences physiological responses such as respiration, skin conductance, and heart rate (Gomez and Danuser 2007).

Although empirical evidence is sparse, tempo and mode may be particularly important determinants of listeners' responses to music with regard to consumer behavior (Kellaris and Kent 1991). Tempo refers to the speed or pacing of a musical piece measured in beats per minute (BPM), whereas mode is a musical variable that defines the specific configuration of musical intervals used within a scale, a chord, or a piece of music (Sadie and Tyrrell 2001). The ability to perceive and process these characteristics is often considered universal or hard-wired in human beings. In light of recent research, these two properties appear to be distinctive attributes of virtually all music, operating independently of geographic or other cultural contextual variance (Harwood 1976; Fritz et al. 2009; Bowling et al. 2009). In fact, virtually every piece of music consists of a series of musical events in time, which-like any other event occurring in time-follow each other in a particular tempo. Similarly, virtually every piece of music exhibits a kind of underlying tonal system comprising its tonal structure (i.e., mode). We now turn to a discussion of the potential effects of each of these musical elements on customer responses.

\subsection{Effects of tempo}

Research from the fields of musicology, psychology, and consumer behavior suggests that tempo is one of the most important determinants of human response to music. The high impact of tempo (i.e., the rate of events in time) may stem from the fact that tempo is applicable not only to music but to a wide range of experiential contexts and that the ability to process music tempo is acquired early in life (Dalla Bella et al. 2001).

Tempo is strongly correlated with arousal. Fast (slow) music has been shown to raise (lower) listeners' self-reported arousal levels (Husain et al. 2002; Balch and Lewis 1996; Chebat et al. 2001; Kellaris and Kent 1993). Further, the effect of tempo on self-reported arousal is reflected in bodily responses to tempo; fast music can increase physiological variables such as heart rate, blood pressure, and breathing rate (Lundin 1985).

Tempo of music can also affect time perception. Oakes (2003) showed that time spans filled with slower music are perceived to be shorter than those filled with faster music. Theoretically, these findings can be explained with recourse to a memory-based "storage size" model of temporal perception. This model postulates that an increase in tempo (i.e., an accelerated frequency of musical events) corresponds to an increase in cognitive data load. The larger the data load to be processed, the larger the allocated memory space and the longer the perceived duration associated therewith (Oakes 2003).

Importantly, a now classic pair of field studies by Milliman (1982, 1986) examined the effects of music varying in tempo on actual customer behavior. 
Milliman's (1982) first study found slower music to decrease pace of in-store traffic flow in a supermarket, thereby leading to greater sales whereas fast music accelerated pace of in-store traffic flow corresponding to lower sales. Milliman's (1986) second published study similarly found that patrons spent more time in a restaurant and consumed more alcoholic beverages under conditions of slow (relative to fast) tempo environmental music.

Thus, existing research raises obvious research questions regarding effects of tempo on customer perceptions and behavior. Can we replicate the Milliman effect, and if so, what structural element(s) of music might interact with, or qualify the effects of tempo? We turn now to one such structural element-musical modewhich may also impact consumer behavior.

\subsection{Effects of mode}

Although many different tonal systems are known and have been used by musicians across different times and cultures (e.g., pentatonic or atonal scales), the major and minor modes (featuring a major versus a minor third, respectively) have been the predominant tonal systems for several centuries in Western music (Meyer 1956). [Hereinafter the term "mode" refers to the major and minor modes.] Previous research regarding mode gives rise to several lines of argument resulting in potentially conflicting predictions when considered in the context of retail atmospherics and consumer behavior.

In Western music, the major and minor modes are known to be strong indicators of positive and negative affective valence (i.e., perceived sadness or happiness; Gagnon and Peretz 2003; Hevner 1935; Peretz et al. 1998). From a developmental perspective, mode appears to be mastered later than tempo as a cue to music valence: At the age of 6 years, children begin to use both tempo and mode to infer the valence of a piece of music, whereas younger children rely solely on tempo in their valence ratings, or they are simply unable to distinguish happy from sad music (Dalla Bella et al. 2001). In addition to being a cue to certain affective states, mode has also been shown to induce mood in listeners (Webster and Weir 2005). In a laboratory experiment conducted by Husain et al. (2002), listening to a piece of music in major mode changed participants' moods in a positive direction, whereas listening to the same piece of music in minor mode had a negative effect on participants' moods. Given prior research on atmospherics showing a positive correlation between mood and customer behavior (Donovan and Rossiter 1982), these findings suggest that music in a major mode (i.e., positively valenced) could lead to greater sales than music in a minor mode (i.e., negatively valenced).

While recent limited evidence suggests that mode may not impact temporal perceptions (Droit-Volet et al. 2010), work in consumer psychology supports the idea that mode influences listeners' temporal perceptions. Kellaris and Kent (1992) found that time spans filled with music in minor mode are perceived as shorter than spans filled with music in major mode. Thus, shoppers exposed to music in minor mode may underestimate actual time spent in a store while those exposed to music in major mode may overestimate perceived time spent. Subjective under- and over-estimations of time can affect actual time spent in a store (Yalch and Spangenberg 2000), thereby leading to respectively prolonged or shortened shopping trips. Important to retailers of course is the fact that customers spending more time in a store are more likely to interact with 
sales personnel, make a greater number of unplanned purchases, and spend more money (Donovan and Rossiter 1982; Inman et al. 2009).

In summary, there is not an overwhelming amount of evidence or theory to suggest specific effects of musical mode on consumer behavior. However, some evidence for an effect of mode exists, and research in atmospherics has shown positive correlations between customer mood, store evaluation, actual time spent in the store, and spending (Donovan and Rossiter 1982). Thus, a further research question we explore herein regards how mode might impact consumer behavior.

\subsection{Interactive effects of mode and tempo}

Shoppers are assailed by a host of sensory impressions in retail environments and, although theoretically interesting and normatively important, interaction of various atmospheric variables has received little research attention. Receiving even less research consideration has been the interaction of specific characteristics (or structural elements) of a single environmental cue such as music.

Past theoretical discussion (Bruner 1990) as well as empirical research across the disciplines of marketing (Kellaris and Kent 1991), psychology (Webster and Weir 2005), and music (Husain et al. 2002) suggests that there may well be normatively significant interaction effects between characteristics of music on customer responses. The work of these several scholars suggests that mode and tempo specifically may have an interactive effect on listener response variables. In the shopping environment, combinations of musical features which can be easily processed should logically put customers at ease, affect their perceptions of the environment, and perceptions of both perceived and actual shopping times thereby increasing approach behaviors (e.g., sales). In many instances, people seem to prefer certain combinations of tempo and mode (e.g., minor-slow or major-fast) to others (e.g., minor-fast). For example, Husain et al. (2002) found fast tempo music led to greater enjoyment ratings in a major mode, whereas slow tempo music led to greater enjoyment in a minor mode. The authors speculate that this may be due either to learned associations of certain typical combinations of mode and tempo, or to modespecific critical speeds. These findings suggest a research question regarding the interactive effect of musical tempo and mode on consumer response. That is, the typical combinations of slow tempo and minor mode, as well as fast tempo and major mode could increase sales volume, while less typical combinations of tempo and mode would correspondingly decrease sales volume.

Our research questions were examined in a field experiment that was conducted in an actual retail setting wherein the structural elements of musical mode and tempo were manipulated and measured while controlling or accounting for exogenous variables.

\section{Experiment}

Music was experimentally manipulated through synchronous playback in three urban locations of a large Swiss department store chain offering a broad range of premium products involving fine foods, wine, clothing, house wares, and 
accessories. Actual gross sales constituted the dependent measure of consumer response in the field experiment. The three stores had each been open for several decades, and thus had relatively stable customer bases. A 2 (mode, minor vs. major) $\times 2$ (tempo, slow vs. fast) full factorial, repeated-measures design was implemented.

\subsection{Procedure}

The main experiment took place over 4 weeks between May 14 and June 10, 2010, a period selected to avoid spring and summer holiday periods as store locations were potentially impacted by nearby university populations. Managerial constraints limited treatment implementations to 3 days per week with each condition assigned to one randomly selected Thursday, one randomly selected Friday, and one randomly selected Saturday to insure a counterbalanced design. Identical experimental conditions were never administered on directly succeeding days to avoid boredom and/or negative staff reactance to the musical selections. Experimental treatments were administered without interruption from open to close; playlists for each condition were played in two alternating a priori randomized orders.

Volume was adjusted such that the music was clearly audible throughout each of the stores (determined by pretesting), while at the same time soft enough to be perceived as a background (as opposed to foreground) stimulus. After initial calibration, volume remained constant across all conditions. Also, other environmental factors such as ambient scent or visual advertising remained unchanged during the experiment.

\subsection{Stimulus materials}

Experimental stimuli were selected from an initial set of 330 songs made available by a commercial retail-business music provider. It is important to note that the 330 songs formed a single music program ("Sophisticated") from this provider, and were relatively homogeneous in terms of global style and genre (original pop/rock songs from the years 1999 to 2009). Moreover, this initial set was representative of a music program that would normally be played in this department store chain. The 330 songs were analyzed using the online music listening algorithm EchoNest API (Jehan 2005). ${ }^{1}$ This analysis provided estimates of the mode (i.e., minor vs. major) and tempo (in BPM) for each song, as well as confidence values for the reliability of each of these estimations. Results of this objective analysis were reviewed by a musicologist and errors were corrected.

Based on the corrected results, songs were classified as minor or major with regard to mode; for tempo, songs slower than $95 \mathrm{BPM}$ or faster than $135 \mathrm{BPM}$ were assigned to slow and fast conditions, respectively. Thus, four stimulus subsets, varying by number of titles they contained (number in parentheses), were created: minor-slow (25), minor-fast (27), major-slow (62), and majorfast (67). The subsets were further reduced to four sets of 24 songs each, including those with the highest overall confidence values (confidence total $=0.5 \times$ confidence $_{\text {mode }}+$ confidence $_{\text {temp }}$ ), resulting in four playlists of equal song number

\footnotetext{
${ }^{1}$ EchoNest API is a free, web-based audio analysis interface (http://developer.echonest.com/docs/v4/)
} 
and approximately equal duration (i.e., 90 minute). The average BPM values of the four playlists closely approximate the 60 versus 140 BPM used by Balch and Lewis (1996) and the 60 versus 165 BPM used by Husain et al. (2002); they are, however, more widely separated than the 114.2 versus 145.3 BPM used by Oakes (2003). The former is arguably a stronger manipulation than the latter due to greater distance between fast and slow conditions. The 90 minute run time was selected because it clearly exceeded the maximum shopping duration of individual customers as reported by store management, thereby minimizing the probability of repeated exposure of any customer to the same song. Table 1 summarizes playlist subset properties.

To account for the possibility of potential confounds between the tempo/mode pairings and musical selection familiarity, several secondary data variables serving as proxies for familiarity of the selections were examined: The number of Google hits for each song, the number of listeners on last.fm ${ }^{2}$ for each song, and the number of times a song had been played by users on last.fm. As the data were non-normally distributed, logarithmic transformations were applied, and all data were standardized. Cronbach's alpha of the three transformed variables was high $(\alpha=0.91)$, indicating high reliability of a composite score constructed using these variables. A significant effect of experimental condition did not manifest for any of the individual variables or for the composite measure (all $p$ 's $>0.05$ ).

\subsection{Dependent variables}

Gross sales data for all checkouts $(N=60)$ across the three stores were collected hourly for each of the 12 days of the field experiment. Individual checkouts served as the unit of observation. If no purchases were recorded for a specific checkout during a given hour, the timeframe was coded as missing. As the sales variable was non-normally distributed, a logarithmic transformation was used to achieve a normal distribution (Fox 2008).

\subsection{Covariates}

Because there were four music conditions and four experimental weeks but only three days per week (Thursday, Friday, and Saturday), it was not possible to assign music conditions equally among days of week. Thus, music condition and week were inherently confounded. To rule out the impact of this potential confound between experimental condition and week of experiment, an additional covariate (i.e., week of experiment at four levels) was included. As turnover and customer shopping patterns (i.e., visits) varied across the three possible treatment days, day of the week was controlled for by recognizing gross sales as lowest on Thursdays, higher on Fridays, and highest on Saturdays. Also, in order to control for known influences of weather on gross sales, meteorological data were obtained from weather stations close to each of the three stores (distances $<6$ miles). ${ }^{3}$ Following the results of Murray et al. (2010), these data were comprised of sunshine duration, humidity, and mean temperature (with temporal resolution of $1 \mathrm{~h}$ ).

\footnotetext{
${ }^{2}$ last.fm is an online music recommendation service (www.last.fm).

${ }^{3}$ Source: Swiss Federal Office of Meteorology and Climatology-MeteoSwiss
} 
Table 1 Playlist properties

\begin{tabular}{llllr}
\hline & \multicolumn{2}{l}{ Playlist } & & \\
\cline { 2 - 5 } & 1 & 2 & 3 & 4 \\
\hline Mode & Minor & Minor & Major & Major \\
Average tempo [BPM] & 85.0 & 161.9 & 82.5 & 157.1 \\
Duration [min] & 92.8 & 92.5 & 93.3 & 90.4 \\
\hline
\end{tabular}

\section{Results}

As measurements of gross sales for individual checkouts were likely to lead to correlated error terms, a linear mixed-model was used to appropriately model the data (Fitzmaurice et al. 2004). Such a model explicitly accounts for unobserved, but constant, heterogeneity between individual checkouts by adding a random intercept to the model. In addition, random intercepts were specified to model the three-level hierarchical structure resultant to checkouts being nested inside store departments, and store departments nested inside stores. Two models were estimated, differing with regard to included predictors, using the lme()-function of the nlme package of the statistical software R (Pinheiro et al. 2011).

The first model contained the objective musical properties and their interaction only (reduced model). This model yielded significant coefficients for mode, tempo, and the interaction term. The second model contained additional fixed effects accounting for the influences of week, day of the week, and weather variables. This model yielded significant coefficients for mode, tempo, the interaction term, the three dummy variables for week, the two dummy variables for day of the week, humidity, and sunshine duration. The temperature variable did not reach significance $(p>0.1)$. This second model yielded a significant improvement in fit compared to the first, reduced model. Summarized results and properties associated with each of the two models are included in Table 2.

Figure 1 graphically depicts the ordinal interaction of mode and tempo on logtransformed sales indicated by the three-level hierarchical structure. Interestingly, while initial examination shows fixed main effects of minor mode and slow tempo on sales, a significant interaction between tempo and mode qualifies these main effects: music in a major mode varied imperceptibly with regard to effectiveness by tempo while music in a minor mode was significantly more effective when accompanied by a slow tempo.

\section{Discussion}

Although compelled by Bruner's (1990) work, little research to date has examined the effects of musical mode and tempo on marketing variables, and certainly none has looked at the interactive effects of these two elements. The current research presents empirical evidence from a field experiment identifying an interaction effect between these structural elements, confirming our suspicion that musical mode is 
Table 2 Comparison of linear mixed models

\begin{tabular}{|c|c|c|c|c|c|c|c|c|}
\hline & \multicolumn{4}{|c|}{ Model 1 (reduced model) } & \multicolumn{4}{|c|}{ Model 2 (full model) } \\
\hline Log-likelihood & \multicolumn{4}{|c|}{$-2,030.237$} & \multicolumn{4}{|c|}{$-1,737.668$} \\
\hline $\mathrm{AIC}$ & \multicolumn{4}{|c|}{$4,076.474$} & \multicolumn{4}{|c|}{$3,507.336$} \\
\hline $\mathrm{BIC}$ & \multicolumn{4}{|c|}{$4,130.902$} & \multicolumn{4}{|c|}{$3,616.172$} \\
\hline \multirow[t]{2}{*}{ McFadden's adjusted $R^{2}$} & \multicolumn{2}{|c|}{0.026} & & & \multicolumn{3}{|c|}{0.164} & \\
\hline & $b$ & SE & $t$ & $p$ & $b$ & SE & $t$ & $p$ \\
\hline Constant & 7.196 & .092 & 78.420 & .000 & 7.701 & .130 & 59.141 & 0.000 \\
\hline Mode (major) & -0.066 & 0.011 & -5.917 & 0.000 & -0.111 & 0.015 & -7.471 & 0.000 \\
\hline Tempo (fast) & -0.076 & 0.011 & -6.808 & 0.000 & -0.120 & 0.012 & -9.887 & 0.000 \\
\hline Mode $\times$ tempo & 0.032 & 0.016 & 2.031 & 0.042 & 0.118 & 0.017 & 6.842 & 0.000 \\
\hline Week 2 & & & & & -0.103 & 0.022 & -4.735 & 0.000 \\
\hline Week 3 & & & & & -0.138 & 0.021 & -6.498 & 0.000 \\
\hline Week 4 & & & & & -0.234 & 0.033 & -7.005 & 0.000 \\
\hline Friday & & & & & 0.049 & 0.012 & 4.068 & 0.000 \\
\hline Saturday & & & & & 0.124 & 0.012 & 10.134 & 0.000 \\
\hline Humidity & & & & & -0.005 & 0.001 & -5.862 & 0.000 \\
\hline Sunshine & & & & & 0.001 & 0.000 & 3.461 & 0.001 \\
\hline Temperature & & & & & -0.006 & 0.004 & -1.600 & 0.110 \\
\hline
\end{tabular}

indeed an additional factor beyond tempo that can significantly influence customer behavior. Our result therefore qualifies the effect of slow tempo on sales reported by Milliman $(1982,1986)$ showing that the positive main effect of slow tempo strongly depends on the mode of the musical selection. Specifically, only minor mode, slow tempo music favorably affected sales volume in our study.

One explanation for our pattern of results may be related to the simple fact that specific, typical combinations of tempo and mode are preferred over others. Relatedly, Husain et al. (2002) found that combinations of slow tempo and minor mode, as well as fast tempo and major mode, led to greater enjoyment ratings than other less typical combinations of tempo and mode. This effect likely stems from

Fig. 1 Fixed effects of tempo and mode on $(\log )$ sales from hierarchical structure (from Table 2: model 2)

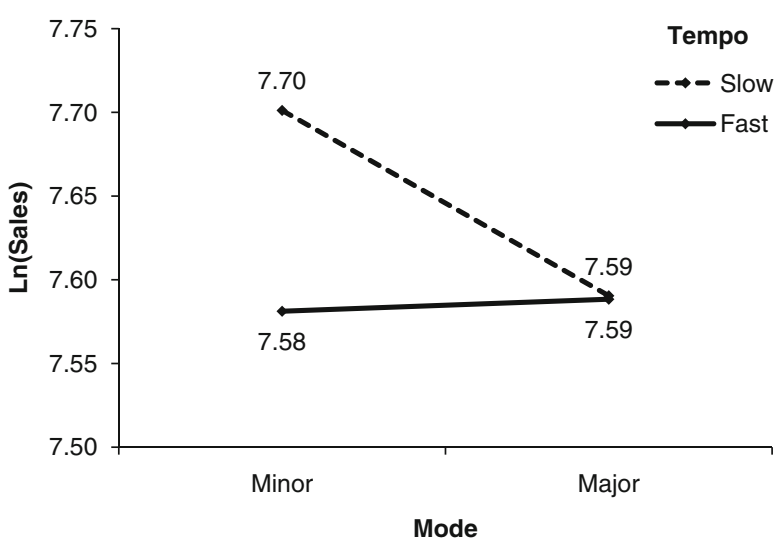


several hundred years of Western music tradition using the slow-minor combination to express sad affective states, while the fast-major combination has most frequently been applied to convey feelings of elation or joy. By way of explanation, both the slow-major and fast-minor conditions contain inconsistent emotional cues (Hunter et al. 2008) and are perceived (by Western listeners anyway) as less typical than the slow-minor or fast-major combinations. Resultant increased levels of enjoyment associated with typical tempo-mode combinations may therefore lead to more positive evaluations of store environments resulting in increased spending consistent with traditional valence-based models of consumption (Donovan and Rossiter 1982). In the fast-major condition, however, this positive interaction is neutralized by the counteractive effect of fast tempo (Milliman 1982, 1986); a customer's pace is accelerated as they move through the store resulting in reduced time spent in the store, and therefore reduced spending.

Our results may also be interpreted in the context of recent research regarding affective consumption. Two distinct streams of literature have shown feelings of sadness to lead to increased spending either consciously (as a means of mood repair) or unconsciously (as a carry-over effect). For example, sad mood inductions have been shown to result in increased food intake (Garg et al. 2007), increased price of product choice (Lerner et al. 2004), and increased spending (Cryder et al. 2008). Given that both slow tempo and minor mode are associated with negative affect (i.e., sadness), music-induced sadness may well explain increased spending behavior in a shopping environment. Consistently, this explanation is supported by Alpert and Alpert (1990), who report consumers' buying intentions increased (decreased) after exposure to sad (happy) music.

It is worth noting that our results, while statistically and normatively significant, are more modest (from an effect size perspective) than those of Milliman's (1982). While Milliman reported an average gross sales increase of $38.2 \%$ between fast and slow conditions, our findings show the minor-slow condition yielding $12 \%$ greater sales than the minor-fast condition. We believe, however, that our results are likely a more realistic estimate of the effect of music tempo on sales due to our control for external influences (e.g., weather), as well as our application of statistical methods accounting for the hierarchical structure and repeated measurements in such data. Milliman did not report accounting for these potential influences on his results.

Though practitioners have relied on tempo as a criterion to design in-store music, little of their attention has been devoted to the mode of musical selections and much less (if any) consideration to the interaction between musical mode and tempo. The findings herein increase awareness regarding these variables, their interaction, and the potential benefits of deliberate application thereof. Specifically, increased sophistication in designing more effective in-store music is suggested by the mode $\times$ tempo interaction found in our work. From a practitioner's perspective, our findings suggest that retailers can improve effectiveness of in-store music by using slow music in a minor mode rather than other combinations of tempo and mode. Practitioners should consider the structural elements of mode and tempo in conjunction or the desired effect (i.e., increased sales) of atmospheric music could be under realized or, taken to the extreme may have a detrimental effect on the bottom line. To efficiently design appropriate playlists for future research or application, researchers and practitioners can adopt the software-based analysis 
method we used to identify and manipulate mode and tempo (described in Stimulus materials).

From an epistemological perspective, the current research should be interpreted in light of a long-running discussion in social psychology and related disciplines. In several publications across many years, Cialdini and colleagues (Cialdini 2009; Goldstein et al. 2008) have strongly argued that one should study naturally occurring behaviors in a "full-cycle." That is, in the interests of more complete scientific knowledge we should study phenomena not only in the laboratory, but also in the real-life environments within which they occur. Essentially, Cialdini argues that social scientists should assign greater value to field research than has historically been the case in many disciplines. This call for greater field study of factors influencing human behavior is supported by the empirical findings of Anderson et al. (1999) who show that the sizes and directions of effects are often highly correlated across laboratory and field experiments. These authors also suggest that the external validity of laboratory experiments and the internal validity of field experiments are both often higher than many researchers previously assumed. Thus, while the current field experiment furthers the tradition of previous studies on music in a retail context, it also contributes to our basic scientific understanding regarding effects of the structural elements of music upon people's behavior.

The current work, while providing evidence of an important interaction between two structural properties of music, certainly raises issues motivating further research. It would be compelling to examine the influence of mode and tempo as a function of time of day. It may be that time of day affects preferred stimulation levels of shoppers, and musical variables could thus be further tailored to provide optimal levels of stimulation. Further, the question arises from our work as to whether the influence of different levels of mode and tempo vary across specific store departments and/or product categories. For example, musical treatments may have differential effects for low- versus highinvolvement products. Perhaps most compelling, future research should examine the processes underlying our findings. We particularly encourage looking at factors driving behavior - examining the main and interactive effects of musical mode and tempo on customers' affective and cognitive responses including variables like mood as well as real versus perceived shopping times.

\section{References}

Alpert, J. I., \& Alpert, M. I. (1990). Music influences on mood and purchase intentions. Psychology and Marketing, 7(2), 109-133. doi:10.1002/mar.4220070204.

Anderson, C. A., Lindsay, J. J., \& Bushman, B. J. (1999). Research in the psychological laboratory: truth or triviality? Current Directions in Psychological Science, 8(1), 3-9. doi:10.1111/1467-8721.00002.

Areni, C. S., \& Kim, D. (1993). The influence of background music on shopping behavior: classical versus top-forty music in a wine store. Advances in Consumer Research, 20(1), 336-340.

Balch, W. R., \& Lewis, B. S. (1996). Music-dependent memory: the roles of tempo change and mood mediation. Journal of Experimental Psychology: Learning, Memory, and Cognition, 22(6), 13541363. doi:10.1037/0278-7393.22.6.1354.

Bowling, D. L., Gill, K., Choi, J. D., Prinz, J., \& Purves, D. (2009). Major and minor music compared to excited and subdued speech. The Journal of the Acoustical Society of America, 127(1), 491-503. doi:10.1121/1.3268504.

Bruner, G. C. (1990). Music, mood, and marketing. Journal of Marketing, 54(4), 94-104. doi:10.2307/1251762. 
Caldwell, C., \& Hibbert, S. A. (2002). The influence of music tempo and musical preference on restaurant patrons' behavior. Psychology and Marketing, 19(11), 895-917. doi:10.1002/mar.10043.

Chebat, J.-C., Chebat, C. G., \& Vaillant, D. (2001). Environmental background music and in-store selling. Journal of Business Research, 54(2), 115-123. doi:10.1016/S0148-2963(99)00089-2.

Cialdini, R. B. (2009). We have to break up. Perspectives on Psychological Science, 4(1), 5-6. doi:10.1111/j.1745-6924.2009.01091.x.

Cryder, C. E., Lerner, J. S., Gross, J. J., \& Dahl, R. E. (2008). Misery is not miserly: sad and selffocused individuals spend more. Psychological Science, 19(6), 525-530. doi:10.1111/j.14679280.2008.02118.x.

Dalla Bella, S., Peretz, I., Rousseau, L., \& Gosselin, N. (2001). A developmental study of the affective value of tempo and mode in music. Cognition, 80(3), B1-B10. doi:10.1016/S0010-0277(00)00136-0.

Donovan, R. J., \& Rossiter, J. R. (1982). Store atmosphere: an environmental psychology approach. Journal of Retailing, 58(1), 34-57.

Droit-Volet, S., Bigand, E., Ramos, D., \& Bueno, J. L. O. (2010). Time flies with music whatever its emotional valence. Acta Psychologica, 135(2), 226-232. doi:10.1016/j.actpsy.2010.07.003.

Fitzmaurice, G., Laird, N., \& Ware, J. (2004). Applied longitudinal analysis. Wiley series in probability and statistics. Hoboken: Wiley.

Fox, J. (2008). Applied regression analysis and generalized linear models. Thousand Oaks: Sage Publications.

Fritz, T., Jentschke, S., Gosselin, N., Sammler, D., Peretz, I., Turner, R., Friederici, A. D., \& Koelsch, S. (2009). Universal recognition of three basic emotions in music. Current Biology, 19(7), 573-576. doi:10.1016/j.cub.2009.02.058.

Gagnon, L., \& Peretz, I. (2003). Mode and tempo relative contributions to "happy-sad" judgements in equitone melodies. Cognition \& Emotion, 17(1), 25-40. doi:10.1080/02699930302279.

Garg, N., Wansink, B., \& Inman, J. J. (2007). The influence of incidental affect on consumers' food intake. Journal of Marketing, 71(1), 194-206. doi:10.1509/jmkg.71.1.194.

Garlin, F. V., \& Owen, K. (2006). Setting the tone with the tune: a meta-analytic review of the effects of background music in retail settings. Journal of Business Research, 59(6), 755-764. doi:10.1016/j. jbusres.2006.01.013.

Goldstein, N. J., Cialdini, R. B., \& Griskevicius, V. (2008). A room with a viewpoint: using social norms to motivate environmental conservation in hotels. Journal of Consumer Research, 35(3), 472-482. doi:10.1086/586910.

Gomez, P., \& Danuser, B. (2007). Relationships between musical structure and psychophysiological measures of emotion. Emotion, 7(2), 377-387. doi:10.1037/1528-3542.7.2.377.

Hargreaves, D. J., \& North, A. C. (1997). The social psychology of music. New York: Oxford University Press.

Harwood, D. L. (1976). Universals in music: a perspective from cognitive psychology. Ethnomusicology, 20(3), 521-533. doi:10.2307/851047.

Hevner, K. (1935). The affective character of the major and minor modes in music. The American Journal of Psychology, 47(1), 103-118. doi:10.2307/1416710.

Hunter, P., Schellenberg, E. G., \& Schimmack, U. (2008). Mixed affective responses to music with conflicting cues. Cognition \& Emotion, 22(2), 327-352. doi:10.1080/02699930701438145.

Husain, G., Thompson, W. F., \& Schellenberg, E. G. (2002). Effects of musical tempo and mode on arousal, mood, and spatial abilities. Music Perception, 20(2), 151-171. doi:10.1525/mp.2002.20.2.151.

Inman, J. J., Winer, R. S., \& Ferraro, R. (2009). The interplay among category characteristics, customer characteristics, and customer activities on in-store decision making. Journal of Marketing, 73(5), 1929. doi:10.1509/jmkg.73.5.19.

Jehan T. (2005). Creating music by listening. PhD thesis, Massachusetts Institute of Technology, Cambridge, MA.

Kellaris, J. J. (2008). Music and consumers. In C. P. Haugtvedt, P. M. Herr, \& F. R. Kardes (Eds.), Handbook of consumer psychology (pp. 837-856). New York: Taylor \& Francis Group/Lawrence Erlbaum Associates.

Kellaris, J. J., \& Kent, R. J. (1991). Exploring tempo and modality effects on consumer responses to music. Advances in Consumer Research, 18(1), 243-248.

Kellaris, J. J., \& Kent, R. J. (1992). The influence of music on consumers' temporal perceptions: does time fly when you're having fun? Journal of Consumer Psychology, 1(4), 365-376. doi:10.1016/S10577408(08)80060-5.

Kellaris, J. J., \& Kent, R. J. (1993). An exploratory investigation of responses elicited by music varying in tempo, tonality, and texture. Journal of Consumer Psychology, 2(4), 381-401. doi:10.1207/ s15327663jcp0204_03. 
Lerner, J. S., Small, D. A., \& Loewenstein, G. (2004). Heart strings and purse strings. Psychological Science, 15(5), 337. doi:10.1111/j.0956-7976.2004.00679.x.

Lundin, R. W. (1985). An objective psychology of music (3rd ed.). Malabar: R.E. Krieger Pub. Co.

McAdams, S., Winsberg, S., Donnadieu, S., De Soete, G., \& Krimphoff, J. (1995). Perceptual scaling of synthesized musical timbres: common dimensions, specificities, and latent subject classes. Psychological Research, 58(3), 177-192. doi:10.1007/BF00419633.

Meyer, L. B. (1956). Emotion and meaning in music. Chicago: The University of Chicago Press.

Milliman, R. E. (1982). Using background music to affect the behavior of supermarket shoppers. Journal of Marketing, 46(3), 86-91. doi:10.2307/1251706.

Milliman, R. E. (1986). The influence of background music on the behavior of restaurant patrons. Journal of Consumer Research, 13(2), 286-289. doi:10.1086/209068.

Morrison, M., \& Beverland, M. (2003). In search of the right in-store music. Business Horizons, 46(6), 77-82. doi:10.1016/S0007-6813(03)00092-2.

Morrison, M., Gan, S., Dubelaar, C., \& Oppewal, H. (2011). In-store music and aroma influences on shopper behavior and satisfaction. Journal of Business Research, 64(6), 558-564. doi:10.1016/j. jbusres.2010.06.006.

Murray, K. B., Di Muro, F., Finn, A., \& Popkowski Leszczyc, P. (2010). The effect of weather on consumer spending. Journal of Retailing and Consumer Services, 17(6), 512-520. doi:10.1016/j. jretconser.2010.08.006.

North, A. C., Hargreaves, D. J., \& McKendrick, J. (2000). The effects of music on atmosphere in a bank and a bar. Journal of Applied Social Psychology, 30(7), 1504-1522. doi:10.1111/j.1559-1816.2000. tb02533.x.

North, A. C., Shilcock, A., \& Hargreaves, D. J. (2003). The effect of musical style on restaurant customers' spending. Environment and Behavior, 35(5), 712-718. doi:10.1177/0013916503254749.

Oakes, S. (2003). Musical tempo and waiting perceptions. Psychology and Marketing, 20(8), 685-705. doi:10.1002/mar. 10092 .

Park, C. W., \& Young, S. M. (1986). Consumer response to television commercials: the impact of involvement and background music on brand attitude formation. Journal of Marketing Research, 23 (1), 11-24. doi:10.2307/3151772.

Peretz, I., Gagnon, L., \& Bouchard, B. (1998). Music and emotion: perceptual determinants, immediacy, and isolation after brain damage. Cognition, 68(2), 111-141. doi:10.1037/a0013790.

Pinheiro J., Bates D., DebRoy S., Sarkar D., \& the R core team (2011). nlme: linear and nonlinear mixed effects models. R-Package version 31-102.

Sadie, S., \& Tyrrell, J. (2001). The new Grove dictionary of music and musicians (2nd ed.). New York: Grove.

Spangenberg, E. R., Grohmann, B., \& Sprott, D. E. (2005). It's beginning to smell (and sound) a lot like Christmas: the interactive effects of ambient scent and music in a retail setting. Journal of Business Research, 58(11), 1583-1589. doi:10.1016/j.jbusres.2004.09.005.

Turley, L. W., \& Milliman, R. E. (2000). Atmospheric effects on shopping behavior: a review of the experimental evidence. Journal of Business Research, 49(2), 193-211. doi:10.1016/S0148-2963(99) 00010-7.

Vida, I., Obadia, C., \& Kunz, M. (2007). The effects of background music on consumer responses in a high-end supermarket. International Review of Retail, Distribution \& Consumer Research, 17(5), 469-482. doi:10.1080/09593960701631532.

Webster, G. D., \& Weir, C. G. (2005). Emotional responses to music: interactive effects of mode, texture, and tempo. Motivation and Emotion, 29(1), 19-39. doi:10.1007/s11031-005-4414-0.

Wilson, S. (2003). The effect of music on perceived atmosphere and purchase intentions in a restaurant. Psychology of Music, 31(1), 93-112. doi:10.1177/0305735603031001327.

Yalch, R. F., \& Spangenberg, E. (1993). Using store music for retail zoning: a field experiment. Advances in Consumer Research, 20(1), 632-636.

Yalch, R. F., \& Spangenberg, E. R. (2000). The effects of music in a retail setting on real and perceived shopping times. Journal of Business Research, 49(2), 139-147. doi:10.1016/S0148-2963(99)00003-X. 